\section{Public Health Genomics}

Public Health Genomics 2010;13:336-344

DOI: $\underline{10.1159 / 000262328}$
Received: April 6, 2009

Accepted after revision: July 27, 2009

Published online: November 26, 2009

\title{
Patient Physical Characteristics and Primary Care Physician Decision Making in Preconception Genetic Screening
}

\author{
V.L. Bonham ${ }^{a}$ S. Knerr ${ }^{a} \quad$ W.G. Feero ${ }^{b} \quad$ N. Stevens ${ }^{c} \quad$ J.F. Jenkins ${ }^{b} \quad$ C.M. McBride ${ }^{a}$ \\ ${ }^{a}$ Social and Behavioral Research Branch and ${ }^{b}$ Genomic Healthcare Branch, National Human Genome Research \\ Institute, NIH, Bethesda, Md., and ' University of Washington School of Medicine, Seattle, Wash., USA
}

\section{Key Words}

Ancestry • Decision making • Ethnicity · Genetic screening • Guidelines $\cdot$ Physical features $\cdot$ Preconception $\cdot$ Race

\begin{abstract}
Background: There has been growing emphasis on preconception care as a strategy to improve maternal and child health since the 1980s. Increasingly, development of genetic tests will require primary care providers to make decisions about preconception genetic screening. Limited research has been conducted on how primary care providers interpret patients' characteristics and use constructs, such as ethnicity and race, to decide whom to offer preconception genetic screening. Objective: This report assessed the influence of patient characteristics on decisions to offer preconception genetic screening. Methods: A web-based survey of family physicians was conducted. Physicians reviewed a clinical vignette that was accompanied by a picture of either a black or a white patient. Physicians indicated whether they would offer genetic screening, and if yes, what tests they would offer and what factors influenced their decisions. Results: The majority (69.2\%) of physicians reported that they would not offer genetic screening. Respondents who reviewed the vignette accompanied by a picture of the black patient were more likely to offer screening (35\% vs. $26 \%, p=0.0034$ ) and rated race as more important to their
\end{abstract}

decision to offer testing than those who viewed the picture of the white patient ( $76 \%$ vs. $49 \%, p<0.0001)$. Conclusions: Our findings suggest that patient race is important to physicians when making decisions about preconception genetic testing and that decision making is influenced by patients' physical characteristics. The reticence of physicians in this sample to offer preconception screening is an important finding for public health and clinical practice.

Copyright $\odot 2009$ S. Karger AG, Basel

Despite recent medical and technological advances and widespread implementation of prenatal care, adverse pregnancy outcomes remain a major public health concern in the United States. $12 \%$ of babies are born premature, $8 \%$ are born with low birth weight, and $3 \%$ have major birth defects. Additionally, 31\% of women giving birth suffer pregnancy complications [1]. Most troubling, though, is that improvements in maternal and infant pregnancy outcomes have slowed significantly and in some cases deteriorated since the 1980s [2]. In response, there has been growing emphasis on preconception care (defined as a set of interventions that aim to identify and modify biomedical, behavioral, and social risks to a woman's health or pregnancy outcome through prevention and management) [3].

\section{KARGER}

() 2009 S. Karger AG, Basel

Fax +4161306 1234

E-Mail karger@karger.ch

www.karger.com
Accessible online at:

www.karger.com/phg
Vence L. Bonham, J.D.

Social and Behavioral Research Branch

National Human Genome Research Institute, NIH

31 Center Drive, Bldg. 31, Room B1B55, Bethesda, MD 20892-2152 (USA)

Tel. +1 301594 3973, Fax +1 301480 3066, E-Mail bonhamv@ mail.nih.gov 
The Centers for Disease Control and Prevention (CDC) released recommendations for improving preconception health and health care in 2006. These recommendations were developed by a CDC/Agency for Toxic Substances and Disease Registry Preconception Care Work Group and a panel of external partners through review of published research and existing professional practice standards and guidelines. The CDC recommendations use classifications originally developed by the American Academy of Pediatrics and American College of Obstetricians and Gynecologists (ACOG) in their 'Guidelines for Perinatal Care' that define 4 domains of preconception care interventions: physical assessment, risk screening, vaccinations, and counseling. One of 8 areas within the domain of risk screening is genetic risk assessment [4]. Genetic risk assessment performed as a part of preconception care gives women reproductive options that would not be available if screening was performed at a later point in time, including time to obtain follow-up testing for test validation, not having specific diagnostic options limited by gestational age, and allowing discussions of reproductive planning to occur without concern about the outcome of an ongoing pregnancy [5].

The 2006 CDC recommendations to improve preconception health and health care called for the creation of guidelines for physicians on preconception risk assessment through screening [6]. Existing genetic testing and screening guidelines released by professional organizations make recommendations about whom to offer testing: usually high-risk individuals, defined as those with a family history of the disorder, or members of racial, ancestral, or ethnic groups with high rates of the disorder relative to the general population. For example, ACOG recommends that individuals of African, Southeast Asian, and Mediterranean descent be offered carrier screening for hemoglobinopathies, which include sickle cell disease and the thalassemias, due to their high frequency in these population groups. They qualify this recommendation, however, by saying, 'It should be noted that ethnicity is not always a good predictor of risk because individuals from at-risk groups may marry outside their ethnic group' [7].

Similarly, in 2001 ACOG and the American College of Medical Genetics (ACMG) issued guidelines for cystic fibrosis carrier screening. These guidelines recommended that carrier testing be offered to Caucasian couples, including Ashkenazi Jews, who are planning a pregnancy or seeking prenatal care, and that it also be made available to all patients $[8,9]$. These guidelines were updated in 2005 , again stating that screening should be offered be- fore conception or in early pregnancy when both partners are of Caucasian, European, or Ashkenazi Jewish ethnicity, and that information about screening should be made available to all couples. This time, however, they added that 'it is reasonable to offer cystic fibrosis carrier screening to all couples regardless of race or ethnicity as an alternative to selective screening' [10].

Controversy surrounds carrier screening that targets specific groups, both in terms of what criteria should be used to identify individuals who are members of highrisk populations and the impact of increasing racial and ethnic admixture on implementing such criteria. Disagreement in these domains makes exploring the influence of primary care physicians' perceptions of patient characteristics on the types of screening offered a question of interest [11]. Little is known about the implementation or effectiveness of genetic testing guidelines published by professional organizations like ACOG or ACMG. Specifically, the patient factors primary care providers consider when making decisions to offer preconception genetic services are poorly understood.

The objective of this study was to assess the factors influencing family physicians' decisions of whether or not to offer preconception genetic screening using a clinical vignette that did not describe the race, ethnicity, or ancestry of the patient, but was accompanied by a picture of either a black or a white woman. We surveyed family physicians because they have identified the importance of genomic medicine to the field, they provide much of the health maintenance, family planning, and chronic disease care for women, and they have articulated the role of the specialty in translating preconception care into clinical practice [12].

\section{Methods}

Study Sample

Subjects were recruited from the membership of the American Academy of Family Physicians (AAFP), the national association of family doctors. The AAFP is one of the largest national medical organizations, with more than 94,000 members within the 50 states, D.C., Puerto Rico, the Virgin Islands, and Guam.

In January 2005, prior to implementation of the AAFP Annual Clinical Focus on Genomics curriculum, 10,000 AAFP members were randomly selected to participate in a web-based survey. Selected physicians were sent invitation e-mails from the AAFP that described the study's purpose, risks and benefits of participating, and provided participants a URL to access the survey online. Invitations were sent in 2 groups of 5,000 members each. The sample was stratified by years since completing residency, such that half of the invitations went to physicians who had completed residency over 15 years earlier. Two reminder e-mails 
Fig. 1. Images of the 2 patients presented to physicians.
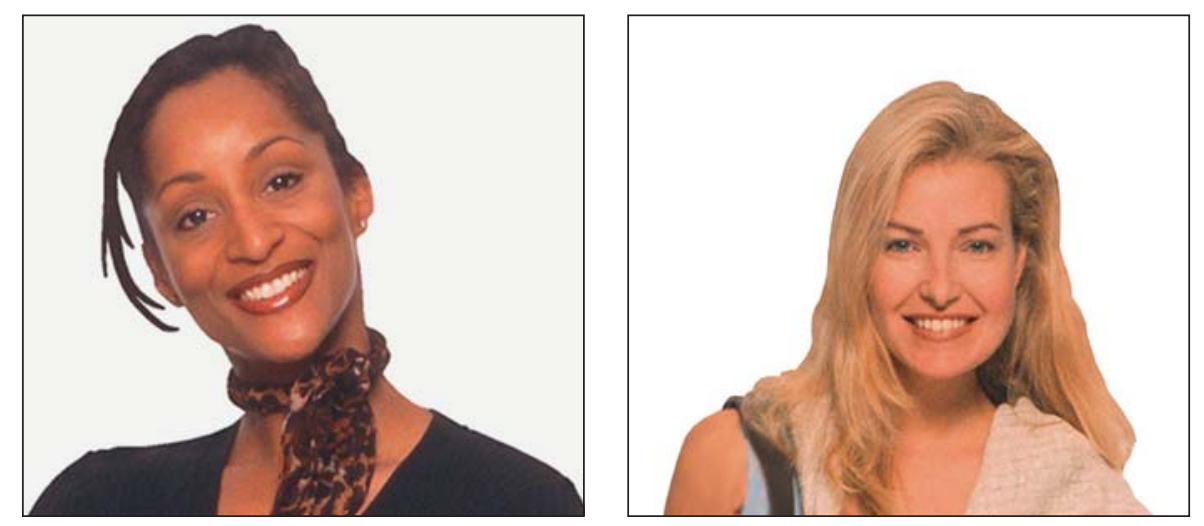

were sent within 2 weeks of the original invitations. As an incentive to participate, physicians who completed the survey were entered into a lottery to win 1 of 6 iPods. The survey was available online for 3 weeks and took approximately 30 minutes to complete. The survey was designed for web-based administration and located at a portal on the AAFP home page. The study was reviewed and approved by both the National Institutes of Health and the AAFP institutional review boards.

\section{Survey Instrument}

Physicians were asked about recommendations for genetic screening in response to a clinical vignette. Physicians were randomly assigned to view the vignette - which did not describe the patient's race, ethnicity, or ancestry - with a picture of either a black or a white patient (fig. 1). They were then asked if they would offer genetic screening; if yes, what conditions and what factors had influenced their decision. The vignette was presented as follows:

'Monica is a healthy woman, age 36, who has commercial insurance through her employer. She is in your office for her annual physical exam. She informs you that she is thinking about becoming pregnant for the first time. She does not know of any genetic diseases in her family or in her partner's family. She comes to your office for medical counsel.'

After this vignette, physicians were asked to respond 'yes' or 'no' to the question: 'Would you offer any genetic screening/testing?' Those who answered 'yes' were then asked: 'What screening/testing would you offer? (Check all that apply)', with the possible choices being: '(a) Amniocentesis, (b) $\alpha$-thalassemia, (c) $\beta$-thalassemia, (d) Cystic fibrosis, (e) Canavan disease, (f) Familial dysautonomia, (g) Hartnup disease, (h) Maternal serum $\alpha$-fetal protein (MSAFP), (i) Sickle cell disease, (j) Tay-Sachs disease, (k) Other, (l) Specified other'.

The same subset of physicians was then asked the question: 'What factors influenced your offer? (Check all that apply)', with the possible choices being: '(a) Age, (b) Ancestry, (c) Cost, (d) Ethnicity, (e) Family history, (f) Health insurance, (g) Race, (h) Other, (i) Specified other'.

Other relevant characteristics assessed in the survey included characteristics of the practice setting, time spent in research and with patients, knowledge of United States Preventive Services Task Force guidelines, and self-identified race and ethnicity. We acquired the physicians' gender and years since residency through the AAFP membership database. Input on the list of conditions from which physicians could select to offer testing was received from 2 genetic counselors.

\section{Statistical Analyses}

Descriptive statistics and correlations were conducted. Physician characteristics included gender, number of years since residency completion, working in an academic environment, and time spent with patients. A $\chi^{2}$ test of independence was used to analyze relationships between the patient's skin color (black or white), decisions to offer screening, and the types of screening test offered. Throughout this report $\mathrm{p}<0.05$ is used as the criterion for statistical significance.

\section{Results}

1,035 physicians completed the web-based survey, representing a response rate of $10 \%$. Physicians who reported spending less than $10 \%$ of their time with patients were excluded to confine analyses to participants who were active care providers $(n=994)$. Table 1 presents descriptive statistics of the 994 respondents. Participating physicians were comparable to those who did not respond, with the only difference being that respondents involved in research were overrepresented in the sample compared to the AAFP membership as a whole (18 vs. 9\%) [13]. Of the 994 family physicians, 26 did not view the vignette, leaving 968 total respondents in the final sample. Roughly half of the 968 respondents saw a picture of the black patient $(n=495)$ and roughly half saw a picture of the white patient $(\mathrm{n}=473)$. There were no significant differences between physicians who saw the black and white patient for the characteristics listed in table 1.

\section{Offering Preconception Screening/Testing}

Generally, physicians said they would not offer screening/testing in response to the clinical vignette. Of the 968 
physicians who saw the vignette 965 responded to the question whether they would screen the patient and 668 (69\%) reported that they would not offer screening/testing to the patient. For physicians who saw the black patient, there were a number of characteristics that were significantly associated with offering genetic testing, including female gender $(\mathrm{p}=0.0080)$, completing residency less than 15 years earlier $(\mathrm{p}=0.0062)$, and working in a university, teaching, or residency training environment $(\mathrm{p}<0.0001)$. Interestingly, there were no significant associations between physician characteristics and offering genetic testing for those who saw the white patient (table 2).

\section{Differences in Screening/Testing Offers between Patients}

Physicians were 1.5 times more likely to offer genetic screening/testing to the black patient than to the white patient $(p=0.0034)$. Among those who would offer screening, physicians were more likely to offer screening/ testing for sickle cell disease, $\alpha$-thalassemia, and $\beta$-thalassemia to the black patient than the white patient (sickle cell: 78.4 vs. $7.3 \%, p<0.0001 ; \alpha$-thalassemia: 15.1 vs. $5.7 \%, \mathrm{p}=0.0113$; $\beta$-thalassemia: 18 vs. $9 \%, \mathrm{p}=0.0278$ ). Additionally, among those who would offer screening,
Table 1. Characteristics of the 994 survey respondents

\begin{tabular}{lc}
\hline Characteristic & Respondents, \% (n) \\
\hline $\begin{array}{l}\text { Mean age, years } \\
\text { Gender }\end{array}$ & $45.6(984)$ \\
$\quad$ Male & $67.34(668)$ \\
Female & $32.66(324)$ \\
Race & \\
$\quad$ White & $75(743)$ \\
Asian & $7(67)$ \\
Hispanic & $4(39)$ \\
Black & $2(24)$ \\
Other & $3(29)$ \\
Not specified & $9(92)$ \\
Board certified & $96.38(958)$ \\
Practice setting & \\
Small (solo or 2-person partnership) & $18.69(171)$ \\
Other practice setting & $81.31(744)$ \\
Years since residency completion & \\
$\quad<5$ & $18.71(186)$ \\
5-15 & $36.22(360)$ \\
$>15$ & $45.07(448)$ \\
In university, teaching, or residency & \\
training environment & $29.46(269)$ \\
Time spent with patients & \\
15-30\% & $9.01(81)$ \\
$31-60 \%$ & $10.46(94)$ \\
$61-90 \%$ & $37.49(337)$ \\
$>90 \%$ & $43.05(387)$ \\
\hline &
\end{tabular}

Table 2. Physicians offering genetic screening/testing by respondent characteristic

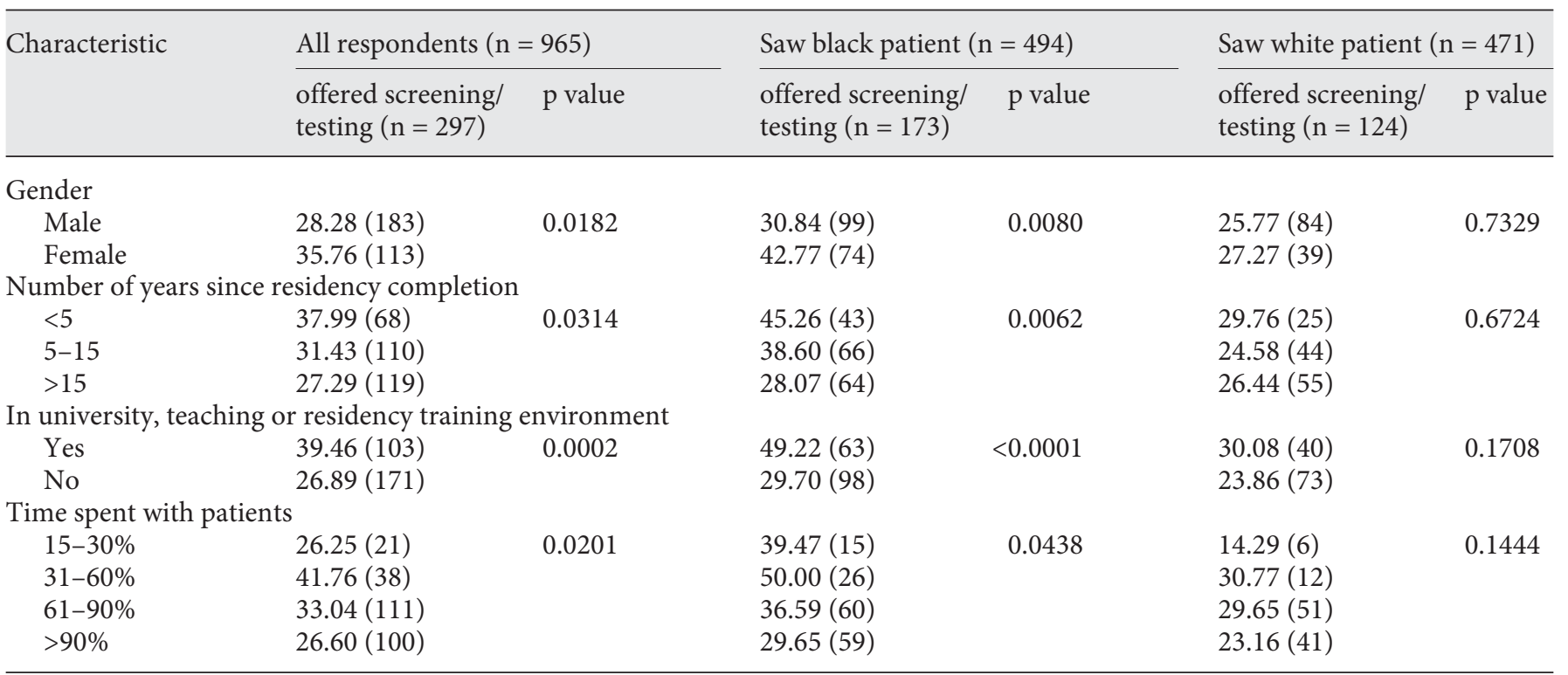

Figures are percentages with numbers in parentheses. $28 \%$ of male physicians offered screening/testing. $31 \%$ of male physicians that saw the black patient offered screening/testing. $26 \%$ of male physicians that saw the white patient offered screening/testing. Not all physicians answered all survey items. 
Table 4. Factors influencing respondents' decisions to offer preconception genetic screening/testing

\begin{tabular}{llllr}
\hline Factor & $\begin{array}{l}\text { Overall (non-missing } \\
\mathrm{n}=294), \%(\mathrm{n})\end{array}$ & $\begin{array}{l}\text { Saw black patient (non- } \\
\text { missing } \mathrm{n}=172), \%(\mathrm{n})\end{array}$ & $\begin{array}{l}\text { Saw white patient (non- } \\
\text { missing }=122), \%(\mathrm{n})\end{array}$ & p value \\
\hline Age & $88.10(259)$ & $85.47(147)$ & $91.80(112)$ & 0.0982 \\
Ancestry & $17.69(52)$ & $16.86(29)$ & $18.85(23)$ & 0.6592 \\
Cost & $13.95(41)$ & $12.21(21)$ & $16.39(20)$ & 0.3075 \\
Ethnicity & $39.12(115)$ & $43.60(75)$ & $32.79(40)$ & 0.0611 \\
Family history & $27.55(81)$ & $26.74(46)$ & $28.69(35)$ & 0.7131 \\
Health insurance & $8.84(26)$ & $6.40(11)$ & $12.30(15)$ & 0.0792 \\
Race & $64.97(191)$ & $76.16(131)$ & $49.18(60)$ & $<0.0001$ \\
\hline
\end{tabular}

Three physicians ( 1 saw the black patient, 2 saw the white patient) did not answer this survey question. This is reflected in the non-missing $\mathrm{n}$ provided in the column headings.

proxy for race is interesting to note, as current guidelines for carrier testing frequently describe populations using ethnicity or geographic ancestry rather than race. There is substantial debate in the field of human genetics about the relationship between race and genetic variation, namely whether self-identified race can serve as a proxy for an individual genetic background [16-18]. Additionally, there can be heterogeneity between an individual's self-identified race, the race that healthcare providers may perceive them as identifying with, and their actual genetic background, which further complicates decision making in offering preconception genetic testing. Thus, questions of importance are what types of screening should have been offered to each patient and what factors should be weighed in making these decisions.

There were 4 disorders where significant differences were seen in genetic testing offers between the 2 patients: sickle cell disease, $\alpha$-thalassemia, $\beta$-thalassemia, and cystic fibrosis. For physicians offering testing, screening for sickle cell disease was offered by over three quarters (78.5\%) of the physicians who saw the black patient and less than $10 \%$ of the physicians who saw the white patient. Screening for $\alpha$ - and $\beta$-thalassemia was also offered more frequently by physicians who saw the black patient and offered testing (table 3). Current ACOG Clinical Management Guidelines recommend offering carrier screening for the hemoglobinopathies (sickle cell disease and the thalassemias) to individuals of African, Southeast Asian, and Mediterranean descent [7]. We believe that physicians who saw the black patient were more likely to interpret her physical features as indicating that she belonged to one of these high-risk groups than physicians who saw the white patient. Sickle cell screening was of- fered by the physicians who saw the black patient at a higher rate than any other type of genetic screening/testing. This suggests that physicians have knowledge of the prevalence of sickle cell disease individuals of African descent in the United States.

Screening for cystic fibrosis was offered by $49 \%$ of the physicians who saw the white patient and by $26 \%$ of the physicians who saw the black patient (table 3). The 2001 ACOG recommendations were explicitly revised in 2005 to state that cystic fibrosis carrier screening should be offered when both partners are of Caucasian, European, or Ashkenazi Jewish ethnicity and that it is reasonable to offer cystic fibrosis carrier screening to all couples regardless of race or ethnicity as an alternative to selective screening [10]. Similar to physicians who saw the black patient and subsequently offered testing for the hemoglobinopathies, it is likely that physicians who saw the white patient interpreted her physical features as indicating that she belonged to one of the high-risk groups for cystic fibrosis. The ACOG guidelines on cystic fibrosis screening are not static and have evolved since the implementation of ACOG-recommended population-based carrier screening in 2001. As this process is seen as a model for the successful integration of preventative molecular medicine into routine primary care [19] it is of interest that cystic fibrosis screening was not offered at a higher rate to both patients.

As scientific knowledge about genetic diseases has grown, it has become apparent that there are differences in the incidence and prevalence of disease-causing mutations between population groups. Current carrier testing guidelines have struggled with defining population groups that will benefit from testing for specific muta- 
tions [9, 19-21], which is reflected in their use of multiple constructs to define high-risk groups, namely race, ethnicity, and ancestry [7, 10, 22-24]. How these constructs correlate with genetic variation and their usefulness in clinical practice is a subject of heated debate [25-27]. It has been established, though, that physical characteristics may correlate with race and ethnicity, but that they are weakly correlated proxies for these categories and do not reflect individual genetics [28].

The ability of many genetic tests to reliably detect carriers can vary depending on the panel's composition and the individual's genetic history, as is the case with the current cystic fibrosis screening panel. This necessitates a reliable way to estimate individual genetic background in order to communicate relative risk information, which presents a significant challenge for physicians implementing existing genetic screening/testing guidelines, both in terms of targeting high-risk populations and providing relative risk information. Though better than estimates based on physical features, the weaknesses of self-identified race and ethnicity (SIRE) as a proxy for individual genetics raises questions of under which conditions, if any, SIRE is good enough for guiding clinical decisions. Recently, ancestry has been suggested as a potentially more accurate indicator of genetic background [29] than SIRE, but our findings suggest that the concepts of geographic ancestry and descent may not resonate with physicians, who may base decisions on interpretations of physical features and common views of race. Addressing these issues now is essential to the integration of genetic risk assessment into preconception care, as the complexity of defining the correlation between individual genetics, physical features, and racial, ethnic, or ancestral group memberships will only increase as the United States population becomes more heterogeneous and the frequency of admixture continues to increase [11, 30].

Several limitations should be considered when interpreting these results. First, physicians offering genetic screening/testing in response to the clinical vignette offered amniocentesis and maternal serum $\alpha$-fetal protein at the highest rates. Additionally, they listed age most frequently as a factor influencing their decision to offer testing. The physicians may have interpreted the scenario as asking what genetic screening/testing they would offer to the patient during that visit as well as in the future when she becomes pregnant. As maternal age is a risk factor for fetal chromosomal abnormalities assessed by amniocentesis and MSAP during pregnancy, offering these tests to the patient they were provided is consistent with current clinical recommendations and guidelines. It is also pos- sible that physicians who responded to the clinical vignette misunderstood the patient's status, assuming she was pregnant. Such a misinterpretation of a scenario dealing with reproductive genetics is not entirely surprising. Prenatal care has been a mainstream intervention since the 1980s and is familiar to family physicians. Interventions that identify and modify risks for future pregnancies are less common to family physicians, with estimates showing that only 1 in 4 currently provides ageappropriate preconception care [1].

Additionally, there were a number of factors relating to physician decision making that were not measured with this survey. While some conclusions can be drawn about physicians' perceptions of the patient's race, ethnicity, and ancestry based on the types of tests they offered, these perceptions were not measured directly. Also, while factors that influenced physicians' decisions to offer any genetic testing/screening are known, those that influenced specific testing offers were not measured. Variation may exist between factors that influence decisions to offer specific genetic tests. Exploring these differences will provide a more complete understanding of physician decision making in the context of preconception genetic testing. Finally, we do not know what additional information, if any, physicians would have wanted to collect from the patient before making decisions about offering genetic testing. It is possible that the number of physicians who would offer genetic screening/testing or the patterns of tests offered would change in a scenario where physicians were able to gather information from the patient in addition to that presented in the vignette.

Finally, our response rate of $10 \%$ was low. Physicians are known to be a difficult population to survey [31], and the family physicians who completed the survey were representative when compared to the overall American Association of Family Physicians membership [13]. Also our sample was not sufficiently diverse with respect to race and ethnicity to use physicians' self-reported race/ ethnicity as an analytic variable. It should be noted that our results only provide information about the preconception genetic screening practices of family physicians and not other primary care specialties. These areas should be explored further; it is possible that physicians' decision making and preconception genetic screening behaviors may vary with respect to physicians' self-identified race/ ethnicity and specialty.

In conclusion, our results emphasize the need to widely convey the importance of preconception genetic screening as a component of preconception care to primary care providers. This should be recognized as an 
important public health issue [32]. Additionally, only $28 \%$ of physicians who offered genetic screening/testing indicated that family history was a factor that influenced their decision. Our respondents may have interpreted the vignette to suggest that the patient's family history of genetic disorders was negative, but these findings still highlight that emphasis of family history as a powerful risk assessment tool and indicator for genetic testing is needed [33,34]. Finally, our results also speak to the need to clarify existing guidelines for carrier screening, both in terms of how they describe targeted population groups and how they are interpreted and applied by physicians. Primary care providers need to understand the relationships between physical features, self-identified race and ethnicity, ancestry, and human genetic variation. Further research on how these concepts are used in clinical decision making, including the implications for use of preconception genetic screening, is needed and specific guidelines for preconception care should be developed.

The correlation between physical characteristics and individual genetics is weak at best. Successful application of targeted preconception carrier screening will depend on the development of quick and reliable ways to collect information from patients about their geographic ances- try. However, the United States population is becoming more diverse, and the use of ancestry to guide targeted preconception carrier screening is not the only public health strategy to consider. Universal preconception screening for certain conditions may be a better approach and would certainly be less challenging to implement from an educational standpoint than a strategy based on fluid definitions of race, ethnicity, and ancestral background. Additional research is needed to better understand the benefits and costs of offering all patients seeking preconception care a standard array of carrier screening tests.

\section{Acknowledgements}

This research was supported (in part) by the Intramural Research Program of the National Human Genome Research Institute, National Institutes of Health. The content is solely the responsibility of the authors and does not represent the official position of the National Human Genome Research Institute, National Institutes of Health, or the Department of Health and Human Services. We thank Amanda Parsad and Julie Williams for their statistical expertise and Adebola O. Odunlami for her involvement in the study development. We thank the reviewers for their thoughtful comments which improved this article.

\section{References}

1 Centers for Disease Control and Prevention: Preconception health and care, 2006 - at a glance. Atlanta, GA, 2006. Available at http://www.cdc.gov/ncbddd/preconception/ documents/at-a-glance-4-11-06.pdf.

2 Atrash HK, Johnson K, Adams M, Cordero JF, Howse J: Preconception care for improving perinatal outcomes: the time to act. $\mathrm{Ma}-$ tern Child Health J 2006;10:S3-S11.

3 Freda MC, Moos MK, Curtis M: The history of preconception care: evolving guidelines and standards. Matern Child Health J 2006; 10:S43-S52.

4 American Academy of Pediatrics, American College of Obstetricians and Gynecologists: Guidelines for Perinatal Care, ed 5. Elk Grove Village, IL, American Academy of Pediatrics, 2002.

5 Shapira SK, Dolan S: Genetic risks to the mother and the infant: assessment, counseling, and management. Matern Child Health J 2006;10:S143-S146.

-6 Johnson K, Posner SF, Biermann J, Cordero JF, Atrash HK, Parker CS, Boulet S, Curtis MG, Centers for Disease Control and Prevention: Recommendations to improve preconception health and health care - United
States. A report of the CDC/ATSDR Preconception Care Work Group and the Select Panel on Preconception Care. MMWR Recomm Rep 2006;55:1-23.

7 Williams J, ACOG Committee on Practice Bulletins: Hemoglobinopathies in pregnancy - ACOG Practice Bulletin No. 78. Obstet Gynecol 2007;109:229-237.

8 American College of Obstetricians and Gynecologists, American College of Medical Genetics: Preconception and Prenatal Carrier Screening for Cystic Fibrosis: Clinical and Laboratory Guidelines. Washington, DC, ACOG; Bethesda, MD, ACMG, 2001.

$\checkmark$ Grody WW, Cutting GR, Klinger KW, Richards CS, Watson MS, Desnick RJ, Subcommittee on Cystic Fibrosis Screening, Accreditation of Genetic Services Committee, American College of Medical Genetics: Laboratory standards and guidelines for population-based cystic fibrosis carrier screening. Genet Med 2001;3:149-154.

10 American College of Obstetricians and Gynecologists: Update on carrier screening for cystic fibrosis - ACOG Committee Opinion No. 325. Obstet Gynecol 2005;106:14651468 .
- 11 Pletcher BA, Gross SJ, Monaghan KG Driscoll DA, Watson MS: The future is now: carrier screening for all populations. Genet Med 2008;10:33-36.

12 Dunlop AL, Jack B, Frey K: National recommendations for preconception care: the essential role of the family physician. J Am Board Fam Med 2007;20:81-84.

13 Warshauer-Baker E, Bonham VL, Jenkins J, Stevens N, Page Z, Odunlami A, McBride C: Physicians' beliefs about the role of genetics in health differences and the importance of race/ ethnicity and gender in clinical decision making. Community Genet 2008;11:352-358.

14 Frey K, Files J: Preconception health care; what women know and believe. Matern Child Health J 2006;10:S73-S77.

15 Moos MK: Preconceptional health promotion: progress in changing a prevention paradigm. J Perinat Neonat Nurs 2004;18:2-3.

-16 Tang H, Quertermous T, Rodriguez B, Kardia SL, Zhu X, Brown A, Pankow JS, Province MA, Hunt SC, Bowerwinkle E, Schork NJ, Risch NJ: Genetic structure, self-identified race/ethnicity and confounding in casecontrol association studies. Am J Hum Genet 2005;76:268-275. 
17 Bamshad M: Genetic influences on health does race matter? JAMA 2005;294:937-946.

18 Collins FS: What we do and don't know about 'race', 'ethnicity', genetics and health at the dawn of the genome era. Nat Genet 2004;36:S13-S15.

>19 Grody WW, Cutting GR, Watson MS: The Cystic Fibrosis mutation 'arms race': when less is more. Genet Med 2007;9:739-744.

-20 Sugarman EA, Rohlfs EM, Silverman LM, Allito BA: CFTR mutation distribution among U.S. Hispanic and African American individuals: evaluation in cystic fibrosis patient and carrier screening populations. Genet Med 2004;6:392-399.

-21 Aspinall PJ, Dyson SM, Anionwu EN: The feasibility of using ethnicity as a primary tool for antenatal selective screening for sickle cell disorders: pointers from the research evidence. Soc Sci Med 2003;56:285297.

-22 Gross SJ, Pletcher BA, Monaghan KG: Carrier screening in individuals of Ashkenazi Jewish descent. Genet Med 2008;10:54-56.
23 American College of Obstetricians and Gynecologists Committee on Genetics: Screening for Tay-Sachs disease - Committee Opinion No. 318. Obstet Gynecol 2005;106: 893-894.

24 American College of Obstetricians and Gynecologists Committee on Genetics: Prenatal and preconception carrier screening for genetic diseases in individuals of Eastern European Jewish descent - ACOG Committee Opinion No. 298. Obstet Gynecol 2004; 104:425-428.

25 Braun L, Fausto-Sterling A, Fullwiley D, Hammonds EM, Nelson A, Quivers W, Reverby SM, Shields AE: Racial categories in medical practice: how useful are they? PLoS Med 2007;4:1423-1428.

26 Barr DA: The practitioner's dilemma: can we use a patient's race to predict genetics, ancestry and the expected outcomes of treatment? Ann Intern Med 2005;143:809-815.

27 Burchard EG, Ziv E, Coyle N, Gomez SL, Tang H, Karter AU, Mountain JL, Pérez-Stable EJ, Sheppard D, Risch N: The importance of race and ethnic background in biomedical research and clinical practice. $\mathrm{N}$ Engl J Med 2003;348:1170-1175.
28 Cooper RS, Kaufman JS, Ward R: Race and genomics. N Engl J Med 2003;148:11661170 .

29 Jorde LB, Wooding SP: Genetic variation, classification and 'race'. Nat Genet 2004;36: S28-S33.

30 Gilbert F, Schoelkopf J, Li Z: Ethnic intermarriage and its consequences for cystic fibrosis carrier screening. Am J Prev Med 1995;11:251-255.

31 VanGeest JB, Johnson TP, Welch VL: Methodologies for improving response rates in surveys of physicians. Eval Health Prof 2007;30:303-321.

32 Atrash HK, Jack BW, Johnson K, Coonrod DV, Moos M, Stubblefield PG, Cefalo R, Damus K, Reddy UM: Where is the 'W'oman in MCH? Am J Obstet Gynecol 2008;199:S259S265.

33 Solomon BD, Jack B, Feero WG: The clinical content of preconception care: genetics and genomics. Am J Obstet Gynecol 2008;199: S340-S344.

34 Dolan SM, Moore C: Linking family history in obstetric and pediatric care: assessing risk for genetic disease and birth defects. Pediatrics 2007;120:S66-S70. 